\title{
SÍNTESE HISTÓRICA DO HAPKIDÔ COREANO E SUAS CONTRIBUIÇÕES
}

\section{ARTIGO DE REVISÃo}

GAMA, Uberto Afonso Albuquerque da ${ }^{1}$

GAMA, Uberto Afonso Albuquerque da. Síntese histórica do Hapkidô coreano e suas contribuições. Revista Científica Multidisciplinar Núcleo do Conhecimento. Ano. 06, Ed. 09, Vol. 06, pp. 153-167. Setembro 2021. ISSN: 2448-0959, Link de acesso:

https://www.nucleodoconhecimento.com.br/educacao-fisica/hapkidocoreano, DOI: 10.32749/nucleodoconhecimento.com.br/educacao-fisica/hapkidocoreano

\section{RESUMO}

Os pressupostos de sustentação teórica do Hapkido encontram-se intimamente ligados às influências dos povos orientais vizinhos, especialmente da Índia e da China. O objetivo geral deste artigo é apresentar um sucinto histórico desta arte marcial coreana e de seus fundadores. Já os objetivos específicos consistem em ressaltar a importância das técnicas marciais na contemporaneidade e a sua contribuição no desenvolvimento do potencial humano. A metodologia aplicada deuse por meio de uma revisão sistemática de autores do tema no Brasil, na Coreia e nos Estados Unidos. Os resultados mostraram que as opressões que o povo coreano sofreu ao longo de sua história foram os principais motivos pelos quais esta arte marcial foi estruturada de forma bem-organizada e completa. O Hapkido provou a sua relevância no crescimento de grandes nações, na formação de treinadores e na preparação de lutadores e combatentes das Forças Armadas ao promover e desenvolver a disciplina, a ordem e a interação social. Conclui-se, portanto, que é

\footnotetext{
${ }^{1}$ Doutor Honoris Causa em Educação Física pela Cambridge International University; Mestre em Neuropsicanálise; MBA em Administração Esportiva; Especialista em Psicanálise na área de saúde e bem-estar social; Especialista em Psicologia do Desenvolvimento; Licenciado em Filosofia; Profissional de Educação Física CREF 14.394-G/PR; Bacharel em Teologia; Jornalista MTB 10645/DF.
}

RC: 97961

Disponível em: https://www.nucleodoconhecimento.com.br/educacao-fisica/hapkidocoreano 
preciso uma avaliação técnico-científica vinculando esta arte marcial diretamente à filosofia, psicologia, educação física e medicina do esporte, com aplicações práticas para a sociedade e para as comunidades especializadas em todo os continentes, principalmente aos profissionais de Educação Física que poderão valer-se deste conjunto de técnicas como modelo de treinamento para seus alunos.

Palavras-Chave: Hapkido, Treinamento Marcial, Disciplina, Autoestima, Transformação.

\section{INTRODUÇÃO}

Quanto mais instruído e educado e quanto mais culto e preparado um povo, melhor será sua formação pessoal e de cidadania. São muitos os exemplos de países desenvolvidos e ricos que cresceram pela educação e que ampliaram seu progresso em pouco tempo. Todos sabemos que a transformação positiva de uma nação se dá pela educação de seu povo.

É fato que a família, a escola, a sociedade e o governo devem trabalhar juntos oferecendo soluções e implantando ações efetivas que resultem nisso. Assim, é preciso resgatar o desenvolvimento das habilidades psíquica, motora, intelectual, emocional e espiritual de cada indivíduo desenvolvendo a autoconfiança e consciência de ordem, disciplina, generosidade, força, coragem, honra e humildade - fatores importantes para o progresso de uma nação (SHEYA, 2000).

Dessa forma, se observa que o ensino da arte marcial coreana Hapkido[2], tem se mostrado bastante eficaz na transmissão de um espírito cooperativista, de consciência de corporeidade e de motricidade, com princípios éticos e de companheirismo tendo como meta atingir a plena cidadania (LIM, 2017).

A palavra Hapkido quer dizer "caminho harmônico da energia". É uma arte que pode ser praticada por todas as pessoas, de todas as faixas etárias, desde o indivíduo mais jovem até o mais idoso (GAMA, 2019). 
Os pressupostos de sustentação teórica da arte marcial denominada Hapkido encontram-se intimamente ligados às influências dos povos orientais vizinhos especialmente Índia e China. Entretanto, pouco se sabe destas influências e de como o Hapkido pode contribuir para o desenvolvimento do potencial humano. Perante este contexto, o presente artigo tem como objetivo geral realizar um sucinto histórico desta arte marcial coreana e de seus fundadores.

Segundo Amaral (2020), o Hapkido tem know-how para desenvolver o processo de recuperação de crianças e jovens que revelam distúrbios de comportamento social, tanto na convivência familiar como na unidade escolar, eliminando a violência e a hostilidade, e estimulando a fraternização, o bem-estar social e o respeito entre todas as pessoas.

\section{HAPKIDO: UMA ARTE DE FORÇA E DISCIPLINA}

Originário da Coréia, quando o país ainda não era dividido, o Hapkido tornou-se uma das artes marciais mais completas. Atualmente é uma disciplina militar ministrada nas Forças Armadas em quase todo o mundo por envolver em seu treinamento prático a formação de princípios éticos, morais, filosóficos, técnicos e psicofísicos. (MILLER, 2016).

Entretanto, o Hapkido não é uma arte marcial milenar, como alguns afirmam. O Hapkido é uma arte em processo contínuo de evolução e está pronta para transformar positivamente todas as pessoas (SHEYA, 2000). O Hapkido é uma arte moderna e que foi desenvolvida no século XX por volta da década de 40 . Foi influenciado em suas raízes pelos conceitos do Daitô-ryú Aikijujútsu, uma luta japonesa tradicional transmitida pelo mestre japonês Sôkáku Takêda e que, por sua vez, foi influenciada profundamente por Darúma Taíshi, também conhecido por $\mathrm{Ta}$ Mô ou Boddhidharma[3] (KIM - KIM, 2005). 
Não obstante, todos atribuem ao Mestre Choi Yong-Sul a codificação do Hapkido. Ele foi aluno de sensei Takêda e somente bem mais tarde, reorganizou suas técnicas e golpes ampliando as possibilidades do Hapkido (SHAW, 2011).

Isto transformou o Hapkido em uma nova tendência marcial, efeito já observado pela intervenção de outros grandes professores e mestres com suas metodologias próprias. Sua visão ampla e precisa das técnicas mostrou que o Hapkido viria a ser uma das mais completas do mundo (PELLEGRINI, 2009).

\subsection{UM BREVE RESUMO DA HISTÓRIA}

Segundo Kimm (2005) para se ter um melhor entendimento sobre as possíveis origens do Hapkido e como foi seu desenvolvimento, devemos fazer um breve resumo e voltar analisando o ano de 2.333 a. C., data possível dos registros arqueológicos e históricos do surgimento da Coréia.

E assim, neste período, o povo daquela época encontrava-se insatisfeito com seu modo de vida e começava sua migração gradual para uma vasta região do lado leste da Ásia e que atualmente incluiu o extremo nordeste da China e que se denominava Manchúria. Este povo estabeleceu-se em uma região muito próspera hoje denominada como península coreana em busca de um melhor clima, terras férteis para agricultura, rios e praias para pesca e terras de montanhas para caça para sua sociedade e que formou três reinos controlados pela Rainha Chin Heung: Koguryô, Paekchê e Silla (CALDAS, 2011)

Durante um longo período de migração e estabilização, os sistemas tribais haviam estabelecido que jovens guerreiros deveriam ser treinados na prática das artes de luta com as mãos vazias para proteger todos os membros. Posteriormente, deveriam estar preparados e tecnicamente adestrados no uso de bastões, cajados, lanças entre outras armas. Esta foi uma época muito selvagem e rude, onde apenas sobreviviam os mais fortes e os mais capacitados. As guerras entre os mongóis e chineses eram permanentes (KIMM, 2005).

Com o passar do tempo, o desenvolvimento da arquearia também foi de extrema relevância ligada à equitação. As primeiras tribos empregavam cavalos para caças a

RC: 97961

Disponível em: https://www.nucleodoconhecimento.com.br/educacao-fisica/hapkidocoreano 
longas distâncias e para a defesa da sociedade. Gradualmente, além da arquearia foi sendo incluído o uso de lanças, yon-bom[4], facas, punhais entre outras armas[5].

Posteriormente, os líderes que tinham maiores habilidades, mais capacidades técnicas, formaram um grupo de elite denominado Hwarang-dô. Seus seguidores ou discípulos denominaram-se Nang-dô (SHAW, 2011). O grupo de elite seguia regras rígidas de conduta e lealdade, tanto ao rei como aos amigos e parentes, com bravura e arrojo e que norteavam suas vidas.

\subsection{DISPUTA ENTRE NAÇÕES}

O entendimento histórico deste período é fundamental neste trabalho, para que se possa descrever a contextualização onde o Hapkido teve o seu desenvolvimento e evolução no rol das artes marciais.

O interesse do Japão sobre a Coréia foi aumentando aos poucos e a possibilidade de ocupação e colonização já estava na eminência de acontecer. Houve duas guerras vencidas pelo Japão: a primeira em 1894 até 1895 entre Japão e China; e a segunda de 1904 a 1905 entre Japão e União Soviética. (KIMM, 2005).

Após isso, o Japão aumentou sua presença na península coreana com a intenção de ocupação. E essa invasão ocorreu finalmente em 1910, quando houve o declínio do Império Coreano. Isso se deu por disputas internas de comando o que enfraqueceu os Reinos da Coreia.

Ocorreu então a assinatura do Tratado de Ganghwa ou também conhecido como "Tratado da Amizade Japão-Coréia", celebrado entre o Império do Japão e o Reino Joseon em 1876. Neste momento da história, aconteceu um acordo de coalizão entre a Coréia e o Japão. Mais tarde é assinado outro acordo, o Tratado Eulsa, onde o Império Coreano ganhou proteção do Império Nipônico, dando ares de um Estado independente, mas que, na verdade, estava ficando subordinado à política externa e obrigações junto ao Império do Japão (LIM, 2017).

A Coréia então é ocupada por centenas de milhares de nipônicos, os quais transferem suas residências para aquele país perdendo suas fecundas

RC: 97961

Disponível em: https://www.nucleodoconhecimento.com.br/educacao-fisica/hapkidocoreano 
propriedades, as quais passam a ser tomadas pela força militar iniciando então os embates e disputas entre japoneses e coreanos (KIMM, 2005).

Em 1930, os coreanos foram forçados a migrar para o Japão para executar trabalhos forçados. Muitos outros atos contra os direitos humanos foram praticados. E somente em 1945, ao final da II Grande Guerra Mundial, a União Soviética e os Estados Unidos decidiram intervir e dividir a Coréia, sendo que o Norte ficaria sob o domínio soviético, e o Sul sob o domínio americano. A demarcação seria o paralelo 38, região demarcada pelos russos que estavam estabelecidos na área (SHAW, 2011).

Conforme Kimm (2005), durante a reunião de conferência de Postdam, entre 17 de julho e 02 de agosto de e 1945, União Soviética e Estados Unidos se comprometiam a abandonar a Coréia, deixando dois governos: na Coréia do Sul (Seoul), onde se estabeleceu Syngman Rhee, aliado americano, e na Coréia do Norte (Pyongyang), se estabelece Kim-IL Sung, aliado russo.

As características ditatoriais foram impostas duramente e permanecem até hoje tendo como a fronteira o paralelo 38. Ambos os governantes coreanos do Norte e do Sul queriam a unificação e não a divisão do país (GAMA, 2019).

Mesmo com a reunião de conferência de Postdam tendo sido honrada através da assinatura do tratado de pacificação, o governante norte-coreano, Kim IL Sung, tentou influenciar Josef Stalin, revolucionário comunista e líder político soviético, a invadir a Coréia do Sul e tomá-la a força. Stalin estava receoso por diversos motivos, especialmente pelo fato de o conflito ser conduzido para um confronto violento com os Estados Unidos.

Segundo Shaw (2011), mesmo assim, Josef Stalin concordou em apoiar a Coréia do Norte influenciado por Kim IL Sung. Então, somente em 1949, a China se transformara em Estado comunista, e assim, Josef Stalin na intenção de garantir o apoio da União das Repúblicas Socialistas Soviéticas - URSS - sobre a região asiática, garantiu e abonou Kim IL Sung a invadir a Coreia do Sul em 25 de junho de RC: 97961

Disponível em: https://www.nucleodoconhecimento.com.br/educacao-fisica/hapkidocoreano 
1950, ultrapassando a fronteira do paralelo 38. Inicia-se o confronto militar entre as nações.

Diante deste cenário, a Organização das Nações Unidas - ONU -, emitiu a Resolução 83, em 27 de junho de 1950, que autorizou a intervenção estrangeira para que se eliminasse a hostilidade contra a Coréia do Sul retirando suas tropas, fato que não aconteceu. Assim, a partir disso, os EUA como aliado da Coréia do Sul, enviou milhares de soldados para apoiar a democracia. A intervenção americana foi fundamental, pois os norte-coreanos estavam quase derrotando e tomando a Coréia do Sul. Havia um desequilibro de forças, ou seja, URSS e CHINA lutavam juntas contra Seoul (SHAW, 2011).

Conforme Pellegrini (2009), os Estados Unidos da América entram neste instante no confronto direto dando apoio aos sul-coreanos com a intenção de garantir a democracia da região.

A chamada ofensiva americana denominada Batalha de Inchon, na fronteira do paralelo 38, deu forças aos sul-coreanos e reiniciou-se o processo reverso. Mas, neste instante, a China deu alerta aos EUA que desistissem de invadir, mas assim mesmo o conflito continuou, e as tropas norte-coreanas foram encurraladas pelos EUA. A China, então, enviou milhares de soldados que invadiram o rio Yalu e nova fase da Guerra da Coréia se inicia (KIMM, 2005).

A China envolveu-se na Guerra da Coréia, porque temia que os norte-coreanos fossem vencidos e invadissem o território chinês, onde estava sendo ainda configurada a revolução de Mao Tsé Tung. Além disso, a China já estava convencida da ideologia do comunismo para todo o mundo e não aceitariam a derrota (KIMM, 2005).

Segundo Tedeschi (2006), no final houve novo momento de reunião e ambos os lados assinaram um novo tratado de paz entre 1951 e 1953, onde foi estabelecido o fim da guerra, e até hoje, ambas as Coréias, do Norte e do Sul, permanecem divididas pela rivalidade, o antagonismo e pelos altos ciúmes, disputando quem é a

RC: 97961

Disponível em: https://www.nucleodoconhecimento.com.br/educacao-fisica/hapkidocoreano 
melhor diante do mundo. Observa-se que movimentos políticos em todo o mundo têm sido empregados para a conciliação e unificação das Coréias.

Não obstante, isso tudo fez com que o povo coreano pudesse empreender um novo movimento estratégico utilizando as técnicas já conhecidas de seu país com as técnicas dos invasores estrangeiros, mesclando as artes de guerra (LIM, 2017).

\subsection{A CODIFICAÇÃO DO HAPKIDÔ}

O personagem de maior importância e relevância na história do Hapkido foi o Mestre Choi Yong-Sool. Juntamente com ele outros grandes mestres também realizaram suas codificações estabelecendo uma gama variadíssima de técnicas que abrangem chutes, socos, bloqueios, rolamentos, quedas de diversas formas, combates contra diversos oponentes, meditação, massagem, filosofia e técnicas terapêuticas de cura.

Entre estes grandes mestres, encontramos também o grão-mestre John Pellegrini, ítalo-americano radicado nos Estados Unidos, fundador do International Combat Hapkido Federation; o grão-mestre Ji-Han Jae, sul-coreano radicado nos Estados Unidos, fundador do Sim-Moo Hapkido International Federation - e que contracenou com o famoso Bruce Lee no filme Game of Death ou "Jogo da Morte" ; o grão-mestre Hui Choe, sul-coreano radicado na Califórnia e criador do Kum Moo Kwan Hapkido, e o grão-mestre Kim Hee Song, inspirador do Song Do Kwan, entre outras celebridades (SHAW, 2011).

Ao final da década de 50 , os preceitos e a doutrina do mestre Choi Yong-Sool começaram a ter mais evidência na Coréia pelo fato do comportamento de seus alunos e discípulos ser diferenciado. Todos tinham muita coragem, determinação, força, disposição, humildade e disciplina. Isso poderia ser o início da transformação de uma nação (MILLER, 2016).

Segundo Gama (2019), somente no início dos anos 70 é que o Hapkido chega ao Brasil, com uma migração de diversos mestres coreanos: no Estado do Paraná chega o mestre Hee Song Kim; em Estado de São Paulo com o mestre Kang Byung

RC: 97961

Disponível em: https://www.nucleodoconhecimento.com.br/educacao-fisica/hapkidocoreano 
Ha; em Cruz das Almas - BA, com os irmãos Lim (Jung Do e Jung Duck), entre outros grandes mestres e instrutores internacionais sendo uma codificação contemporânea criada a partir da sistematização de diversas outras artes marciais, com as bases éticas da filosofia oriental, dos códigos de conduta e dos ensinamentos do Zen Budismo.

Enfim, a introdução bem-sucedida do Hapkido no Brasil se deu por duas razões: pela sua efetividade no combate utilizado pelas Forças Armadas e pelo seu caráter filosófico como um caminho de vida oferecendo disciplina, autoconfiança, organização e determinação positiva (GAMA, 2019).

Segundo Caldas (2011), assim sendo, o Hapkido teve sua importância histórica na reconstrução da Coréia juntamente com outras artes de guerra. E um dos segredos do "milagre" sul-coreano foi priorizar a educação como política de governo. E o Hapkido faz parte deste processo educacional. A mentalidade é continuar o trabalho de modernização.

Um dos segredos do "milagre" sul-coreano foi priorizar a educação como política de governo. E a mentalidade é continuar o trabalho de modernização. A partir dos anos 1990, após atingir a universalização de um ensino de boa qualidade, o governo do país decidiu realizar uma nova reforma em seu sistema educativo a fim de aproveitar as oportunidades proporcionadas pela sociedade de informação. O objetivo é investir desde as escolas primárias a fim de colocar a sociedade sul-coreana - cuja renda per capita hoje é mais que o dobro da brasileira, mas menos do que um terço da americana - na vanguarda dos próximos avanços tecnológicos (AMARAL, 2012).

O quadro 1 abaixo apresenta uma listagem das Artes Marciais originárias da Coréia, com seu nome, tradução e fundação ou codificador da arte.

RC: 97961

Disponível em: https://www.nucleodoconhecimento.com.br/educacao-fisica/hapkidocoreano 
Quadro 1 - Artes Marciais Originárias da Coréia

\begin{tabular}{|c|c|c|}
\hline ARTE MARCIAL & TRADUÇĀo & FUNDADOR OU CODIFICADOR \\
\hline $\begin{array}{l}\text { Tae Kwon Do } \\
\text { 태켠도 }\end{array}$ & $\begin{array}{l}\text { Arte de usar os pés e as } \\
\text { mãos na luta }\end{array}$ & General Choi Hong Hi (ITF) \\
\hline $\begin{array}{l}\text { Hap Ki Do } \\
\text { 합기도 }\end{array}$ & $\begin{array}{l}\text { Caminho Harmonioso da } \\
\text { Energia }\end{array}$ & Gräo-Mestre Yong Sul Choi \\
\hline $\begin{array}{l}\text { I Yon Bom } \\
\text { 은봄 }\end{array}$ & Bastōes com corrente & Comandante Lee Duk Moo \\
\hline $\begin{array}{l}\text { Kuk Sull Do } \\
\text { 국수도 }\end{array}$ & $\begin{array}{l}\text { Arte Marcial Coreana } \\
\text { (mix) }\end{array}$ & Grão-Mestre Dr He Young Kimm \\
\hline $\begin{array}{l}\text { Jung Do Sull } \\
\text { 정도 술 }\end{array}$ & $\begin{array}{l}\text { Técnica marcial de saltos } \\
\text { em altura }\end{array}$ & $\begin{array}{c}\text { Grão-Mestre Ahn IL Luk e o irmão } \\
\text { Gräo-Mestre Ahn Kil Won }\end{array}$ \\
\hline $\begin{array}{l}\text { Too Kun Sull } \\
\text { 투쿤술 }\end{array}$ & $\begin{array}{l}\text { Arremesso de facas e } \\
\text { punhais }\end{array}$ & Mestre Byung Ku Choi \\
\hline $\begin{array}{l}\text { Hwa Rang Do } \\
\text { 화랑도 }\end{array}$ & $\begin{array}{l}\text { Grupo de Elite do } \\
\text { Hapkido }\end{array}$ & Grāo-Mestre Joo Bang Lee \\
\hline $\begin{array}{l}\text { KumDo } \\
\text { 금도 }\end{array}$ & $\begin{array}{c}\text { A arte da espada } \\
\text { (jukdô) }\end{array}$ & Grão-Mestre Chong Hak \\
\hline
\end{tabular}

Fonte: Adaptado do Dr. He-Young Kimm, 2005.

\subsection{HAPKIDO E PROJETOS SOCIAIS}

Em algum momento na história após 1950, mais de 1.400 sistemas de combate sofisticados a mãos vazias evoluíram. Kwon Bop[6], por exemplo, emergiu como um termo de guarda-chuva para técnicas de mãos vazias. Su Bak Do e Tae kyon[7] foram dois sistemas de luta com ênfase em chutes baixos e voadores, e Su Sul ou Kum Do foi um sistema diversificado de habilidades com espada. Todas estas

RC: 97961

Disponível em: https://www.nucleodoconhecimento.com.br/educacao-fisica/hapkidocoreano 
técnicas somadas foram, aos poucos, sendo valorizadas e codificadas por Kimm (1985) dando o nome de Kuk Sull (TEDESCHI, 2006).

O Hapkido juntamente com o Taekwondo (outra arte coreana) por sua vez, foram sendo observados e introduzidos nas Forças Armadas dos Estados Unidos da América, depois para outros países da Europa e, finalmente, chegaram ao Brasil, como pudemos ver anteriormente no breve resumo da história.

Atualmente o Hapkido tem despertado muito interesse de vários diretores de escolas, assim como de professores, pelo seu critério de disciplina, ordem, respeito hierárquico e cordialidade (LIM, 2017).

A prática do Hapkido, por exemplo, em algumas escolas brasileiras, tem demonstrado franco progresso e uma melhora sensível dos alunos em comportamento e disciplina, em consciência de corporeidade e autoestima. Entretanto, podemos ainda observar que o Hapkido se mostra muito pouco divulgado na sociedade e com preconceito de alguns sobre esta arte, misturando-a com crendices populares (GAMA, 2019).

Conforme Gama (2019), atualmente o Hapkido está sendo introduzido em algumas escolas estaduais e municipais por iniciativa de alguns instrutores e mestres. Além disso, a referida arte marcial coreana está sendo inserida em diversos projetos educacionais em todo o território nacional por livre iniciativa de diversos profissionais que trabalham na recuperação de jovens delinquentes e marginalizados e que estão adaptando-se com muita facilidade à disciplina e ordem imposta pela arte marcial coreana.

O trabalho com o Hapkido nas escolas estaduais, municipais e particulares na cidade de Curitiba tem como objetivo específico incluir a referida arte marcial como parte do currículo, contudo, em um primeiro momento, a atividade é oferecida como extraclasse e inserida no contraturno.

RC: 97961

Disponível em: https://www.nucleodoconhecimento.com.br/educacao-fisica/hapkidocoreano 
Segundo Kim (2005), ensinar Hapkido é ainda algo novo e diferente, porque muitos os professores ainda não têm conhecimento sobre como trabalhar este conteúdo em suas aulas ou ainda se sentem inseguros por nunca tiveram a oportunidade de desenvolver esta arte.

Ainda que o professor de Educação Física não possua uma formação mais completa ou ampla sobre o Hapkido, é possível trabalhar dentro da conformação escolar convidando um instrutor ou mestre qualificado para ministrar demonstrações da arte.

\subsection{CÓDIGO DE ÉTICA E DISCIPLINA DO HAPKIDO}

Observa-se ainda que o Hapkido, assim como outras artes marciais, possui um código estrito de ética e conduta, com disciplinas e mentais sistematizadas em diferentes graus objetivando um alto desenvolvimento de seus praticantes, instrutores, professores, mestres e grão-mestres voltada para a defesa pessoal - Ho Shin Sull - e preparando o espírito marcial do praticante (KIMM, 2005).

Conforme Kimm (2005), os antigos praticantes de artes marciais seguiram regras rígidas de lealdade, tanto ao rei como aos pais e amigos, e com bravura em combate, com simplicidade e prudência em seu modus vivendus estabelecendo cinco preceitos fundamentais de ética, a saber:

- Ser leal ao Rei;

- Ser obediente e obedecer aos pais;

- Ser leal e honrar os amigos;

- Nunca recuar diante do inimigo;

- Realizar uma morte sensata.

O quadro 2, adaptado de Kimm (2005), traz o Código de ética, demonstrando apresentação do quadro. 
Quadro 2 - Código de Honra do Hapkido

\begin{tabular}{|l|c|}
\hline & 화랑의 영 \\
& STRICT CODE OF HONOR HWARANG DO \\
\hline 하나 & 1-BE LOYAL TO YOUR KING. \\
\hline 두 & 2-BE OBEDIENT AND RESPECT TO YOUR PARENTES. \\
\hline 세 & 3-BE LOYAL AND HONOR TO YOUR FRIENDS. \\
\hline 네 & 4-NEVER RETREAT BEFORE THE ENEMY. \\
\hline 다섯 & 5-TO REALIZE A SENSIBLE DEATH. \\
\hline
\end{tabular}

Fonte: Adaptado do Dr. He-Young Kimm, 2005.

Com o tempo, outras prescrições foram sendo criadas à medida que a sociedade evoluiu e tornou-se mais complexa. E o Hapkido, sendo arte de defesa pessoal, exige disciplina, ordem, autocontrole e hierarquia na aplicação das suas técnicas marciais e de defesa pessoal. Para tanto, o código de ética se faz obrigatório para regular e manter sob controle a aplicabilidade de suas técnicas e a consciência de seus guerreiros (GAMA E GAMA, 2019).

\section{CONSIDERAÇÕES FINAIS}

Em meio aos limites do trabalho exposto, a sondagem da literatura mencionada mostrou a importância histórica do Hapkido e da inclusão desta arte marcial coreana como um dos alicerces preponderantes no desenvolvimento psicofisiossocial da sociedade e sua evidência no desenvolvimento de grandes nações.

RC: 97961

Disponível em: https://www.nucleodoconhecimento.com.br/educacao-fisica/hapkidocoreano 
A sistematização de suas técnicas e vertentes servem de apoio como instrumento educacional para o profissional de Educação Física no treinamento crianças, jovens e adultos trazendo inúmeros benefícios.

Pontua-se que o objetivo geral do trabalho, foi cumprido, tendo sido apresentado o histórico desta arte marcial coreana e de seus fundadores. As pesquisas das referências bibliográficas e os diversos trechos comentados por toda a sua extensão deste artigo permitiram reconhecer de forma mais precisa que o Hapkido é uma ferramenta útil para forjar o caráter, desenvolver a personalidade e produzir o ordenamento disciplinar.

Fica evidente que o papel da arte marcial Hapkido é respeitável e significativo no processo como educacional do equilíbrio de crianças, jovens e adultos. O Hapkido mostra que pode desenvolver uma elevada autoestima não permitindo que o jovem se acovarde diante da imensa tarefa de transformar a sociedade.

O presente artigo amplia a gama de conhecimento sobre as influências sobre a formação do Hapkido e de como este pode contribuir para o desenvolvimento do potencial humano. O tema deste artigo ainda é bastante abundante e demandará que outros colegas aprofundem o assunto. Os pesquisadores devem se ajustar aos meios eletrônicos e à mídia digital na produção de artigos científicos abordando o Hapkido e outras artes marciais interpelando a sua repercussão na sociedade mundial.

Por fim, concluímos que é preciso uma avaliação técnico-científica vinculando o Hapkido e as artes marciais diretamente à filosofia, psicologia, educação física e medicina do esporte, com aplicações práticas para a sociedade e as comunidades especializadas em todo os continentes.

\section{REFERÊNCIAS}

AMARAL, Rodrigo. Ensino de Qualidade é Segredo do Sucesso na Coréia do Sul. 
$<$ https://www.bbc.com/portuguese/noticias/2002/020819_educaro3.shtml>.

Acesso em 20. Mar. 2020.

CALDAS JR, P. Hapkido: o caminho da energia coordenada. São Paulo: online 2011.

GAMA, U. A. A.; GAMA, M. M. Hapkido Song Do Kwan - Sistema Filosófico e Marcial. Ed. Vidya, Curitiba, v. 01. 2019.

GAMA, U. A. A.; Hapkido \& Taekwondo - 0 Song Do. Disponível em:< https://www.hapkidocuritiba.com/o-que-e-song-do >. Acesso em 20. Mar. 2020.

GAMA, U. A. A.; Um Breve Perfil Psicanalítico do Bully ou Agressor. Disponível em: < https://www.nucleodoconhecimento.com.br/psicologia/perfil-psicanalitico-dobully >. Acesso em 12. Fev. 2020.

LIM, Y. K. Hapkido Martial Arts for Kids and Adults. A. Changkwan Co, South Korea, 2017.

MILLER, G. The Hapki Way: The Origins and Usage of Hap and Ki in Hapkido. EUA, Ga Miller Consulting Publishing, 2016.

PELLEGRINI, John. Combat Hapkido: The Martial Art for the Modern Warrior. Florida: Black Belt Books Co, 2009.

KIM, M. Y.; KIM, J. Power Hapkido Essential Techniques. New York: Turtle Publishing \& Sam Kwang Printing Ltd., 2005.

KIMM, He-Young. Kuk Sool - History of Hapkido. Baton Rouge: Jackson College Press, 2005.

Chul Hak - Philosophy of Kuk Sool. Baton Rouge: Jackson College Press, 2005.

RC: 97961

Disponível em: https://www.nucleodoconhecimento.com.br/educacao-fisica/hapkidocoreano 
. Young-U, Hyul Bub and Lee Ron. Baton Rouge, Louisiana, Jackson College Press, 2005.

SHEYA, J. Traditional Hapkido. Florida, U.S. Black Belt Mag. Publishing, 2000.

SHAW, Scott. Hapkido: Korean Art of Self-Defense - Martial Art. Florida, Turtle Publishing, 2011.

TEDESCHI, Marc. Hapkido: an introduction to the art of self-defense. Boston: Weatherhill, London, 2006.

\section{APÊNDICE - REFERÊNCIA NOTA DE RODAPÉ}

2. Pronuncia-se Hap (como no inglês Help), com "H" aspirado; Ki-Dô (com acento circunflexo apenas na pronúncia, não na escrita).

3. Boddhidharma (pronuncia-se "bodidarma"), monge indiano, 28‥ Patriarca do Budismo, fundador do Zen ou Ch'An chinês. O nome Boddhidharma é composto de duas palavras "Boddhi" ( ) que significa "iluminado", e "Dharma" ( ) que significa "lei ou dever".

4. Yon-bom também conhecido com "nunchaku", arma marcial oriental que consiste em dois bastões pequenos conectados por uma corda ou corrente

5. Outras armas que foram sendo desenvolvidas pelo povo coreano, tais como: kung-sa (lança e arquearia), Kumdô (similar ao Kendô), Kisa-Bub (equitação), Dan Kum Sool (atirar facas), takyuk sull (técnicas de luta e contra-ataques), Soo Young Bub (natação e mergulho), entre outras.

6. Pronuncia-se "kombô".

7. Pronuncia-se "subakdô" e "tekion".

RC: 97961

Disponível em: https://www.nucleodoconhecimento.com.br/educacao-fisica/hapkidocoreano 
Enviado: Junho, 2021.

Aprovado: Setembro, 2021. 